\title{
The Impact of Flash Glucose Monitoring on Glycaemic Control as Measured by HbA1c: A Meta-analysis of Clinical Trials and Real-World Observational Studies
}

Mark Evans · Zoë Welsh · Sara Ells · Alexander Seibold

Received: October 14, 2019 / Published online: October 31, 2019

(C) The Author(s) 2019

\section{ABSTRACT}

Introduction: Glycated haemoglobin A1c (HbA1c) is the established standard measurement for assessment of glycaemic control in people with diabetes. Here we report on a metaanalysis of real-world observational studies on the impact of flash continuous glucose monitoring on glycaemic control as measured by HbA1c.

Methods: A total of 271 studies were identified in our search, of which 29 contained data reporting changes in HbA1c over periods from 1 to 24 months that could be used in a statistical analysis. Our meta-analysis focuses on observed change in HbA1c at either 2, 3 or 4 months, in adult or paediatric subjects, as well as a longitudinal analysis up to 12 months in adult subjects. These data were drawn from 25 of the

Enhanced Digital Features To view enhanced digital features for this article go to https://doi.org/10.6084/ m9.figshare.10008089.

M. Evans ( $\square)$

Wellcome Trust/MRC Institute of Metabolic Science, University of Cambridge and Cambridge University Hospitals NHS Foundation Trust, Cambridge, UK

e-mail: mle24@cam.ac.uk

Z. Welsh · S. Ells

Abbott Diabetes Care, Witney, Oxfordshire, UK

A. Seibold

Abbott Diabetes Care, Wiesbaden, Germany studies identified in our initial search. These reported $\mathrm{HbA1c}$ data up to 12 months in a total of 1723 participants with type 1 diabetes (T1D) or type 2 diabetes (T2D) using the FreeStyle Libre $^{\circledR}$ flash glucose monitoring system.

Results: Overall mean change in laboratory HbA1c across study subjects at 2-4 months was $-0.55 \%(95 \%$ CI $-0.70,-0.39)$. Amongst the 1023 adults, mean change in $\mathrm{HbA1c}$ was $-0.56 \%$ (95\% CI $-0.76,-0.36)$; for the 447 children and adolescents, mean change in HbA1c was - 0.54\% (95\% CI - 0.84, - 0.23). Based on regression analysis, the degree of change in HbA1c correlated with the initial HbA1c of the study population. A longitudinal analysis in adult subjects $(n=1276)$ shows that HbA1c fell within the first 2 months and changes were sustained up to 12 months. No significant differences were detected between T1D and T2D.

Conclusion: The meta-analysis reported here confirms that starting the FreeStyle Libre system as part of diabetes care results in a significant and sustained reduction in $\mathrm{HbA} 1 \mathrm{c}$ for adults and children with T1D and for adults with T2D. Funding: Abbott Diabetes Care.

Keywords: Continuous glucose monitoring (CGM); Flash glucose monitoring; HbA1c; Interstitial fluid; Meta-analysis; Real-world observational studies; Self-monitoring blood glucose (SMBG) 


\section{Key Summary Points}

Starting the FreeStyle Libre system as part of daily diabetes care results in a significant reduction in $\mathrm{HbA1c}$ for adults and children with T1D and for adults with T2D.

Adult subjects with T1D or T2D demonstrated a rapid and sustained reduction in HbA1c.

The degree of change in $\mathrm{HbA1c}$ is predicted by the HbA1c at baseline prior to starting the FreeStyle Libre system.

\section{INTRODUCTION}

The evidence that good glucose control, as measured by reduced glycated haemoglobin $\mathrm{A} 1 \mathrm{c}(\mathrm{HbA1c})$, is strongly associated with better outcomes for patients with type 1 diabetes (T1D) or with type 2 diabetes (T2D) is widely accepted. Both the Diabetes Control and Complications Trial (DCCT) Research Group [1] and the UK Prospective Diabetes Study (UKPDS) Group $[2,3]$ demonstrated that a lowering of $\mathrm{HbA1c}$ is associated with clinically significant reductions in microvascular complications and long-term macrovascular disease.

Randomized clinical trials (RCTs) indicate that, in comparison to self-monitoring blood glucose (SMBG) testing, several continuous glucose monitoring (CGM) systems are shown to reduce laboratory-measured $\mathrm{HbA1c}$, as well as measures of hypoglycaemia and glycaemic variability in people with diabetes [4-8]. However, in studies using the FreeStyle Libre flash glucose monitoring system to date, only the single-arm SELFY study showed a significant reduction in HbA1c $(-0.4 \%, p<0.001)$ [9]. Two RCTs, IMPACT and REPLACE, showed no change in HbA1c over 26 weeks comparing the FreeStyle Libre system with SMBG in the total study population $[10,11]$. The IMPACT study was designed to show a reduction in hypoglycaemia rather than HbA1c, with the mean $\mathrm{HbA1c}$ at baseline already at $6.7 \%$. In REPLACE, a significant change in HbA1c was reported in a pre-specified subgroup of subjects under 65 years old. In this subgroup, users of the FreeStyle Libre system experienced a statistically significant HbA1c reduction of $-0.33 \%$ versus SMBG [11]. Importantly though, the FreeStyle Libre system was shown in both IMPACT and REPLACE to reduce measures of hypoglycaemia and glycaemic variability in adults with T1D or T2D on insulin $[10,11]$.

In addition to RCTs, a growing number of real-world observational studies have reported outcomes for people with T1D or T2D using the FreeStyle Libre system, including a change in laboratory-measured HbA1c levels. Given the importance of HbA1c as a measure of glycaemic control in patients with diabetes, we aimed to examine the changes in $\mathrm{HbA} 1 \mathrm{c}$ revealed in these real-world studies.

In a rapidly moving clinical landscape in which treatment decisions must be made in as timely a fashion as possible, the increasing importance of observational studies within meta-analyses is recognised. Although a known limitation of observational studies is their susceptibility to selection bias and reporting bias, guidelines have now been established to address and manage these issues and to help standardise reporting within meta-analyses [12, 13]. The most apt in the context of the current analysis are the Meta-analysis Of Observational Studies in Epidemiology (MOOSE) [12].

The aims of this meta-analysis were threefold: (1) to establish whether use of the FreeStyle Libre flash glucose monitoring system favours a reduction in HbA1c when used by people with T1D or T2D as a replacement for SMBG in their standard care; (2) to identify whether changes in final HbA1c reported in RCTs or real-world observational studies exhibit a dependency on mean initial HbA1c amongst the study population using the FreeStyle Libre system; (3) to identify whether longitudinal changes in HbA1c reported in RCTs or realworld observational studies using the FreeStyle Libre system in adult subjects differ on the basis of length of study and type of diabetes (T1D vs T2D). 


\section{METHODS}

\section{Search Strategy and Study Selection}

A search was conducted across the following abstracting and indexing databases: Allied and Complementary Medicine ${ }^{\mathrm{TM}}$, Analytical Abstracts, BIOSIS Previews ${ }^{\circledR}$, Embase $^{\circledR}$, EMCare $^{\circledR}$, International Pharmaceutical Abstracts, MEDLINE $^{\circledR}$, ToxFile ${ }^{\circledR}$. The searched string of terms and the subsequent selection flow diagram are detailed in Fig. 1. Additionally, two studies were identified through conference abstracts.

A total of 29 studies were identified that reported longitudinal laboratory $\mathrm{HbA1c}$ data in participants with T1D or T2D using the FreeStyle Libre system over periods from 1 to
24 months (Table 1). Our meta-analysis focuses on observed change in HbA1c at either 2, 3 or 4 months, as well as a longitudinal analysis up to 12 months. These data were drawn from 25 of the studies identified in our initial search, as indicated in Table 1. This included participants with T1D $(n=1496)$ or T2D $(n=227)$. Studies were included if data were reported in a manner that could be used in a statistical meta-analysis. Data included observations on children, adolescents and adults with T1D or T2D (Table 1). For the RCTs within this analysis set, the within-intervention arm results have been included, not the between-arm results reported previously. All RCTs and observational studies are reported here as absolute change from baseline to ensure a consistent approach and to reflect the real-world patient-centred outcome,

\section{Searched string}

((Freestyle n/2 (libre OR libreTM)) OR ((libre OR libretm) AND (freestyle OR abbott OR free-style) AND (diabet* OR gluco*)) OR ((Abbott OR abbot OR abott) AND interstit* AND gluco*) OR (ti,ab,mesh,emb,su,if,mq,tn(libre OR libreTM) AND (gluco* OR diabet*)) OR FSL OR FGM OR FGMD OR ((intermittent OR flash) $n / 20$ gluco*) OR isCGM OR is-CGM OR is-CGMD OR iscCGM) AND (hba1c OR a1c OR hba1 a1chb OR ((glycat* OR glycos*) n/1 (a1c OR hemoglobin OR haemoglobin* OR heamoglobin*))) AND py(>2013)

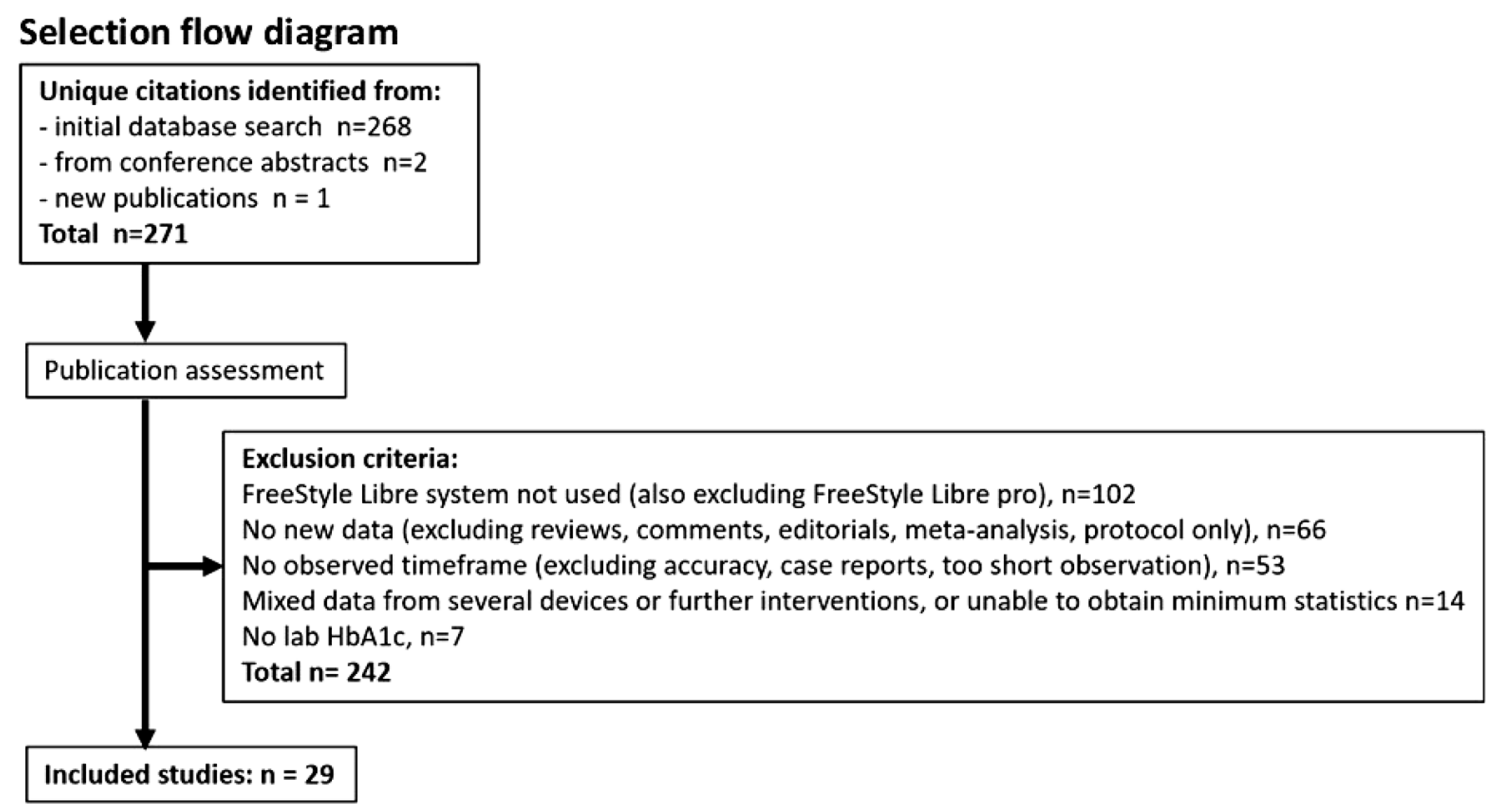

Fig. 1 Search strategy and study selection 
Table 1 Summary of studies with longitudinal data using flash glucose monitoring included in the meta-analysis

\begin{tabular}{|c|c|c|c|c|c|c|c|c|c|}
\hline Study & $\begin{array}{l}\text { Outcome } \\
\text { time } \\
\text { points } \\
\text { (month) }\end{array}$ & $\begin{array}{l}\text { Adults/ } \\
\text { children }\end{array}$ & $\begin{array}{l}\text { Type of } \\
\text { diabetes }\end{array}$ & $\begin{array}{l}\text { Number } \\
\text { of } \\
\text { subjects }\end{array}$ & $\begin{array}{l}\text { Initial } \\
\text { HbAlc } \\
\text { (\%) }\end{array}$ & $\begin{array}{l}\text { Change } \\
\text { in } \\
\text { HbAlc } \\
(\%)\end{array}$ & $\begin{array}{l}S E \\
\text { change } \\
\text { in } \\
\text { HbA1c } \\
(\%)\end{array}$ & $\begin{array}{l}\text { Data used } \\
\text { in analysis } \\
\text { in Figs. } 3 \\
\text { and } 4\end{array}$ & $\begin{array}{l}\text { Data } \\
\text { used in } \\
\text { analysis } \\
\text { in Fig. } 5\end{array}$ \\
\hline $\begin{array}{l}\text { Gibb } 2018 \\
\quad[14]\end{array}$ & 10 & Adults & 1 & 204 & Unknown & -0.27 & 0.082 & & \\
\hline \multirow{2}{*}{$\begin{array}{l}\text { Bolinder } 2016 \\
\quad[10]\end{array}$} & 3 & Adults & 1 & 119 & 6.79 & 0.06 & 0.046 & \multirow[t]{2}{*}{$\checkmark$} & $\checkmark$ \\
\hline & 6 & Adults & 1 & 119 & 6.79 & 0.16 & 0.047 & & $\checkmark$ \\
\hline $\begin{array}{l}\text { Xatzipsalti } \\
2017 \text { [15] }\end{array}$ & 3 & Children & 1 & 51 & 7.06 & -1.00 & 0.269 & $\checkmark$ & \\
\hline $\begin{array}{l}\text { Reddy } 2017 \\
\quad[16]\end{array}$ & 2 & Adults & 1 & 20 & 7.20 & -0.35 & 0.143 & \multirow[t]{2}{*}{$\checkmark$} & $\checkmark$ \\
\hline $\begin{array}{l}\text { Moreno- } \\
\text { Fernandez } \\
2018[17]\end{array}$ & 6 & Adults & 1 & 18 & 7.40 & -0.40 & 0.120 & & $\checkmark$ \\
\hline $\begin{array}{l}\text { Helm } 2016 \\
\quad[18]\end{array}$ & 2 & Children & 1 & 31 & 7.42 & -0.22 & 0.111 & \multirow[t]{2}{*}{$\checkmark$} & \\
\hline $\begin{array}{l}\text { Messaaoui } \\
2018 \text { [19] }\end{array}$ & 12 & Children & 1 & 278 & 7.6 & 0.10 & 0.054 & & \\
\hline $\begin{array}{l}\text { Wijnands } 2017 \\
\text { [20] }\end{array}$ & 3 & Children & 1 & 72 & 7.70 & -0.20 & 0.100 & \multirow[t]{2}{*}{$\checkmark$} & \\
\hline $\begin{array}{l}\text { McKnight } \\
2017 \text { [21] }\end{array}$ & Unknown & Adults & 1 & 169 & 7.73 & -0.23 & 0.056 & & \\
\hline $\begin{array}{l}\text { Campbell } 2017 \\
\text { [9] }\end{array}$ & 2 & Children & 1 & 75 & 7.90 & -0.40 & 0.069 & $\checkmark$ & \\
\hline $\begin{array}{l}\text { Walton- } \\
\text { Betancourth } \\
2017[22]\end{array}$ & 3 & Children & 1 & 47 & 7.93 & -0.09 & 0.079 & $\checkmark$ & \\
\hline $\begin{array}{l}\text { Dover } 2016 \\
{[23]}\end{array}$ & 4 & Adults & 1 & 25 & 8.00 & -0.48 & 0.128 & $\checkmark$ & $\checkmark$ \\
\hline $\begin{array}{l}\text { Bacon } 2017 \\
{[24]}\end{array}$ & 3 & Adults & 1 & 58 & 8.10 & -0.55 & 0.230 & $\checkmark$ & $\checkmark$ \\
\hline \multirow{4}{*}{$\begin{array}{l}\text { Dørflinger } \\
2018 \text { [25] }\end{array}$} & 3 & Adults & 1 & 209 & 8.10 & -0.46 & 0.098 & \multirow[t]{4}{*}{$\checkmark$} & $\checkmark$ \\
\hline & 6 & Adults & 1 & 146 & 8.10 & -0.64 & 0.190 & & $\checkmark$ \\
\hline & 9 & Adults & 1 & 75 & 8.10 & -0.37 & 0.107 & & $\checkmark$ \\
\hline & 12 & Adults & 1 & 25 & 8.10 & -1.01 & 0.305 & & $\checkmark$ \\
\hline
\end{tabular}


Table 1 continued

\begin{tabular}{|c|c|c|c|c|c|c|c|c|c|}
\hline Study & $\begin{array}{l}\text { Outcome } \\
\text { time } \\
\text { points } \\
\text { (month) }\end{array}$ & $\begin{array}{l}\text { Adults/ } \\
\text { children }\end{array}$ & $\begin{array}{l}\text { Type of } \\
\text { diabetes }\end{array}$ & $\begin{array}{l}\text { Number } \\
\text { of } \\
\text { subjects }\end{array}$ & $\begin{array}{l}\text { Initial } \\
\text { HbAlc } \\
\text { (\%) }\end{array}$ & $\begin{array}{l}\text { Change } \\
\text { in } \\
\text { HbA1c } \\
(\%)\end{array}$ & $\begin{array}{l}\text { SE } \\
\text { change } \\
\text { in } \\
\text { HbAlc } \\
(\%)\end{array}$ & $\begin{array}{l}\text { Data used } \\
\text { in analysis } \\
\text { in Figs. } 3 \\
\text { and } 4\end{array}$ & $\begin{array}{l}\text { Data } \\
\text { used in } \\
\text { analysis } \\
\text { in Fig. } 5\end{array}$ \\
\hline $\begin{array}{l}\text { Pintus } 2017 \\
{[26]}\end{array}$ & 3 & Children & 1 & 52 & 8.23 & -0.73 & 0.268 & $\checkmark$ & \\
\hline $\begin{array}{l}\text { Karlsson } 2017 \\
\text { [27] }\end{array}$ & 12 & Adults & 1 & 164 & 8.45 & -0.49 & 0.124 & & $\checkmark$ \\
\hline $\begin{array}{l}\text { Al Hayek } 2017 \\
{[28]}\end{array}$ & 3 & Children & 1 & 47 & 8.50 & -0.66 & 0.238 & $\checkmark$ & \\
\hline \multirow[t]{4}{*}{ Paris 2017 [29] } & 3 & Adults & 1 & 107 & 8.51 & -0.67 & 0.109 & $\checkmark$ & $\boldsymbol{V}$ \\
\hline & 6 & Adults & 1 & 109 & 8.51 & -0.68 & 0.117 & & $\checkmark$ \\
\hline & 9 & Adults & 1 & 104 & 8.51 & -0.48 & 0.118 & & $\checkmark$ \\
\hline & 12 & Adults & 1 & 102 & 8.51 & -0.46 & 0.123 & & $\checkmark$ \\
\hline \multirow{2}{*}{$\begin{array}{l}\text { Abdalaziz } 2018 \\
\quad[30]\end{array}$} & 6 & Adults & 1 & 40 & 8.56 & -0.55 & 0.174 & & $\checkmark$ \\
\hline & 12 & Adults & 1 & 40 & 8.56 & -0.64 & 0.166 & & $\checkmark$ \\
\hline \multirow{2}{*}{$\begin{array}{l}\text { Haak } 2017 \\
{[11]}\end{array}$} & 3 & Adults & 2 & 149 & 8.65 & -0.44 & 0.080 & $\checkmark$ & $\checkmark$ \\
\hline & 6 & Adults & 2 & 149 & 8.65 & -0.27 & 0.083 & & $\boldsymbol{V}$ \\
\hline $\begin{array}{l}\text { Yaron } 2019 \\
\text { [31] }\end{array}$ & 2 & Adults & 2 & 53 & 8.68 & -0.82 & 0.116 & $\checkmark$ & $\checkmark$ \\
\hline $\begin{array}{c}\text { Weiss } 2018 \\
\text { [32] }\end{array}$ & Unknown & Adults & $\mathrm{Mix}^{*}$ & 22 & 8.70 & -1.00 & 0.262 & & \\
\hline \multirow{2}{*}{$\begin{array}{l}\text { Löndahl } 2017 \\
\text { [33] }\end{array}$} & 3 & Adults & 1 & 226 & 8.72 & -0.65 & 0.050 & $\checkmark$ & $\checkmark$ \\
\hline & 12 & Adults & 1 & 226 & 8.72 & -0.74 & 0.063 & & $\boldsymbol{V}$ \\
\hline $\begin{array}{l}\text { Landau } 2018 \\
\text { [34] }\end{array}$ & 3 & Children & 1 & 59 & 8.86 & -0.81 & 0.031 & $\checkmark$ & \\
\hline \multirow{4}{*}{$\begin{array}{l}\text { Ish-Shalom } \\
2016 \text { [35] }\end{array}$} & 1 & Adults & 1 and $2^{\dagger}$ & 6 and $25^{\dagger}$ & 8.90 & -0.80 & 0.178 & & $\checkmark$ \\
\hline & 2 & Adults & 1 and $2^{\dagger}$ & 6 and $25^{\dagger}$ & 8.90 & -1.33 & 0.290 & & $\checkmark$ \\
\hline & 3 & Adults & 1 and $2^{\dagger}$ & 6 and $25^{\dagger}$ & 8.90 & -1.20 & 0.268 & $\checkmark$ & $\checkmark$ \\
\hline & 6 & Adults & 1 and $2^{\dagger}$ & 6 and $25^{\dagger}$ & 8.90 & -1.21 & 0.420 & & $\checkmark$ \\
\hline $\begin{array}{l}\text { Holcombe } \\
2017 \text { [36] }\end{array}$ & 2 & Adults & 1 & 13 & 9.01 & -0.74 & 0.426 & $\checkmark$ & $\checkmark$ \\
\hline $\begin{array}{l}\text { Tirelli } 2017 \\
\text { [37] }\end{array}$ & 3 & Children & 1 & 13 & 9.56 & -1.37 & 0.347 & $\checkmark$ & \\
\hline Hey 2018 [38] & 1 & Adults & 1 & 29 & 9.90 & -0.34 & 0.221 & & $\checkmark$ \\
\hline
\end{tabular}


Table 1 continued

\begin{tabular}{llllllllll}
\hline Study & $\begin{array}{l}\text { Outcome } \\
\text { time } \\
\text { points } \\
\text { (month) }\end{array}$ & $\begin{array}{l}\text { Adults/ } \\
\text { children }\end{array}$ & $\begin{array}{l}\text { Type of } \\
\text { diabetes }\end{array}$ & $\begin{array}{l}\text { Number } \\
\text { of } \\
\text { subjects }\end{array}$ & $\begin{array}{l}\text { Initial } \\
\text { HbA1c } \\
(\%)\end{array}$ & $\begin{array}{l}\text { Change } \\
\text { in }\end{array}$ & $\begin{array}{l}\text { SEA1c } \\
\text { change }\end{array}$ & $\begin{array}{l}\text { Data used } \\
\text { in analysis } \\
\text { in Figs. 3 }\end{array}$ & $\begin{array}{l}\text { Data } \\
\text { used in } \\
\text { analysis } \\
\text { in Fig. 5 }\end{array}$ \\
\hline $\begin{array}{l}\text { Mitchell 2018 } \\
\text { [39] }\end{array}$ & 3 & Adults & 1 & 13 & 10.28 & -0.88 & 0.170 & $\boldsymbol{V}$ & $\boldsymbol{V}$ \\
\hline
\end{tabular}

A total of 29 studies were identified reporting longitudinal HbAlc data in a total of 2396 participants with T1D or T2D using the FreeStyle Libre flash glucose monitoring system. Of these studies, 25 reported longitudinal HbAlc data over 1-12 months in a total of 1723 participants with T1D or T2D using the FreeStyle Libre flash glucose monitoring system. This subset were used in the analysis reported, as identified in the final two columns. The four studies not used in the reported analysis were excluded on the following basis: no initial mean HbAlc was reported [14]; no outcome timings were reported for mean change in HbAlc [21,32]; 12-month outcomes in children only were reported as the study end point [19]

*Mixture of type 1 and type 2, split not reported

${ }^{\dagger}$ Mixture of type $1(n=6)$ and type $2(n=25)$

even within an RCT where a comparator nonintervention group was part of the study protocol. Several of the included studies reported change in laboratory-measured HbA1c for multiple timed end points. For our overall analysis (Figs. 3 and 4) we have included a single end point for each study reflecting the observed change in HbA1c at either 2, 3 or 4 months. For longitudinal analysis in adult subjects (Fig. 5), all relevant timed end points up to 12 months were included.

\section{Compliance with Ethics Guidelines}

This article is based on previously conducted studies and does not contain any studies with human participants or animals performed by any of the authors.

\section{Statistical Analysis}

Meta-analysis of change in HbA1c was performed using a random effects model. Analysis used trial-level data, weighting with the inverse of the within-trial variance. Cochran's heterogeneity statistic $(Q)$ and the $I^{2}$ statistic were calculated [40]. Random effects meta-regression of change in $\mathrm{HbA1c}$ was performed versus initial HbA1c [41]. These are established analytical protocols for meta-analysis of observational data, with known limitations (Fig. 2). A single time point from each study at 2-4 months was used in the main analyses. Comparisons of change in HbA1c in adults between T1D and T2D and time in months since commencing the FreeStyle Libre system were analysed using a random effects meta-regression, with initial HbA1c, type of diabetes and month considered as fixed effects [42]. Longitudinal analysis from baseline to 12 months included longest followup and multiple interim time points from each trial on adult subjects, where available, in order to model temporal effects. Analysis was performed using SAS version 9.4.

Trials are weighted with the inverse of the within-trial variance, i.e. for trials with the same variation between patients, larger trials have more weight but for trials of the same size those with less variation between patients have more weight.

\section{RESULTS}

A forest plot for the overall mean change in HbA1c across study subjects at 2-4 months using the random effects model is shown in Fig. 3a. The areas of the red squares are proportional to the weight of the trial. The 
The meta-analysis included data from the studies compatible with statistical analysis. Limitations of this study are:

- Only flash glucose monitoring arms were considered in this analysis, with no comparison to control subjects, since many of the real-world observational studies did not contain a control group.

- There may be a bias in recruitment of the patients. Entry criteria were not standardised across the studies with few eligibility criteria specified.

- There is potential publication bias.

- Not all studies report how any missing data were handled.

Fig. 2 Limitations of this meta-analysis

included 21 studies are listed in order of mean baseline HbA1c with the highest at the bottom. Across all study subjects $(n=1470)$ the FreeStyle Libre system reduces HbA1c at 2-4 months with an overall mean change in HbA1c of $-0.55 \%$ $(95 \% \mathrm{CI}-0.70,-0.39)$. As expected, there was a substantial degree of heterogeneity between trials $\quad\left[I^{2}=94.1 \%, \quad \tau^{2}=0.09, \quad Q=337.7\right.$ $(p<0.0001)]$. Mean HbA1c change for adult subjects ( $n=1023$, Fig. $3 \mathrm{~b}$ ) across the included studies was $-0.56 \%(95 \%$ CI $-0.76,-0.36)$, with heterogeneity $I^{2}=93.3 \%: \quad \tau^{2}=0.08$, $Q=164.0(p<0.0001)$. For children $(n=447$, Fig. 3c) mean change in HbA1c was $-0.54 \%$ $(95 \%$ CI $-0.84,-0.23)$. Heterogeneity was $I^{2}=93.9 \%: \tau^{2}=0.11, Q=130.3(p<0.0001)$.

The overall mean change in HbA1c with the FreeStyle Libre system as a function of initial HbA1c is shown in the bubble chart in Fig. 4 for the 21 studies with 2-4-month outcomes, where mean initial HbA1c was available. The area of each bubble represents the weight of the trial and the regression line from meta-regression random effects model is displayed. On average, for each percentage increase in mean initial $\mathrm{HbA1c}$, the mean change in final HbA1c falls by $0.31 \%$ (95\% CI -0.43 to -0.19$)$. For example, this analysis indicates that if the mean initial $\mathrm{HbA1c}$ is $8.5 \%$, the expected mean reduction in $\mathrm{HbA} 1 \mathrm{c}$ is $0.60 \%$, a final HbA1c of $7.90 \%$. The mean initial HbA1c explains a considerable proportion of the heterogeneity between studies in change in $\mathrm{HbA1c}$, with $I^{2}$ reducing from $94.1 \%$ to $66.2 \%$. When analysed separately, the slopes were $-0.30(95 \% \mathrm{CI}-0.44$ to - 0.17) and - 0.33 (95\% CI - 0.73 to 0.06 ) for adults and children respectively (data not shown).

Longitudinal outcomes from baseline to 12 months across all studies on 1276 adult subjects are shown in Fig. 5, which includes multiple longitudinal time points within individual studies where available. Importantly, this analysis shows that reductions in mean HbA1c with flash glucose monitoring appear to be sustained. HbA1c falls within the first 2 months, after which the reduction is steady to 12 months. The reduction in HbA1c is statistically significant from 2 months onwards. Data from 12 months (five trials) show a reduction in HbA1c that was similar to 9 months (two trials), 6 months (seven trials) and 3 months (eight trials). No significant differences were detected between adults with T1D $(n=1049)$ or T2D $(n=227)(95 \% \mathrm{CI}-0.51$ to $0.17, p=0.2883)$.

\section{DISCUSSION}

The outcomes from the meta-analysis reported here confirm that using the FreeStyle Libre system can reduce chronic exposure to hyperglycaemia, as measured by laboratory $\mathrm{HbA1c}$, by $0.55 \%$. The changes in HbA1c reported in the 
a

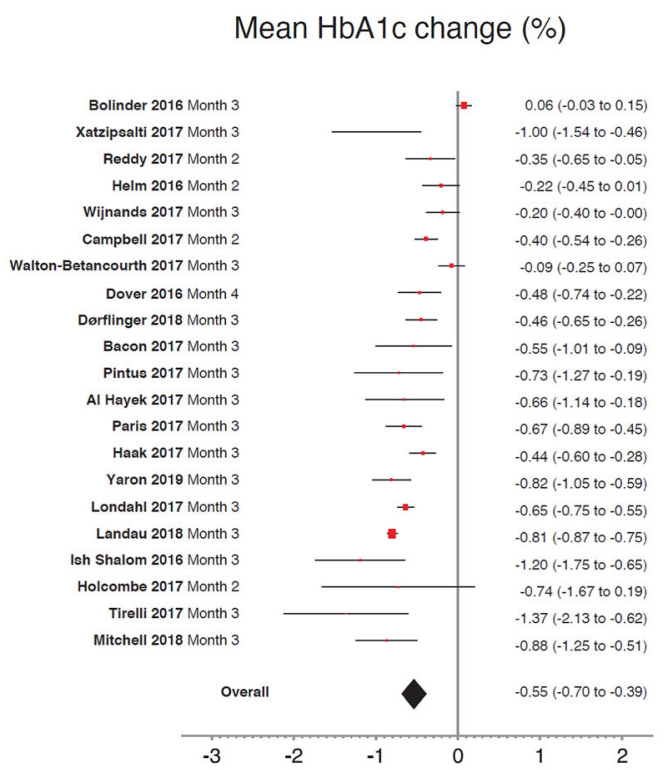

b

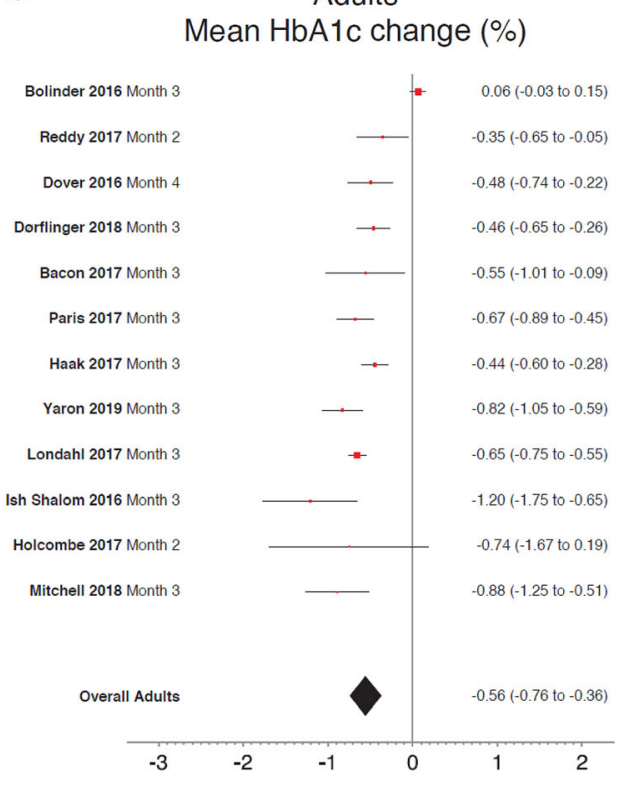

\section{c}

Children

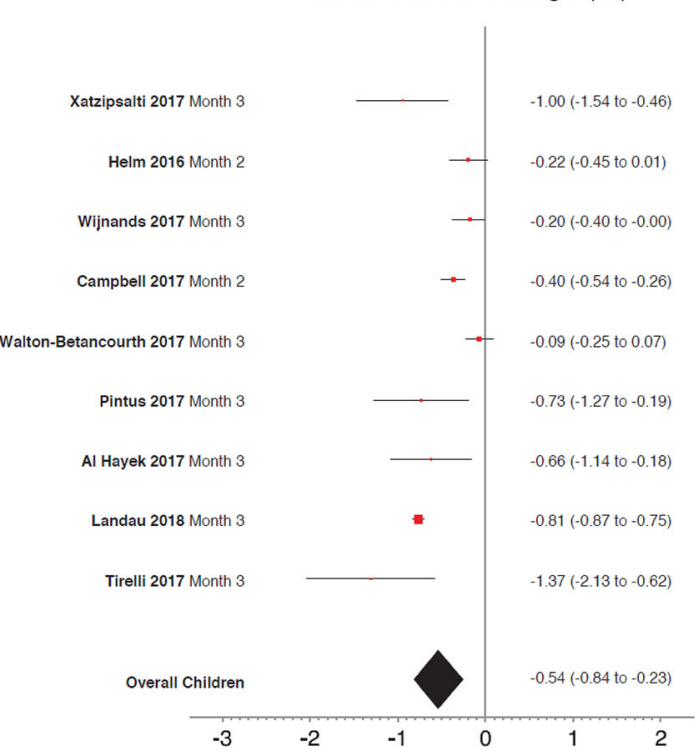

Fig. 3 a Forest plot for change in HbAlc at 2-4 months using random effects model. The areas of the squares are proportional to the weight of the study. A total of 21 studies with 2-4-month outcomes data were included in the analysis and are shown in order of mean initial $\mathrm{HbAlc}$, with the highest at the bottom. Overall mean change in HbAlc was $-0.55,95 \%$ CI $-0.70,-0.39$. Heterogeneity: $\tau^{2}=0.09, Q=337.7(p<0.0001), I^{2}=94.1 \%$. b Forest plot for change in HbAlc at 2-4 months in adult subjects using random effects model. The areas of the squares are proportional to the weight of the study. Twelve studies with 2-4-month outcomes data were included in the analysis. For adults, overall mean change in $\mathrm{HbAlc}$ was $-0.56,95 \% \mathrm{CI}$ $-0.76, \quad-0.36$. Heterogeneity: $\tau^{2}=0.08, Q=164.0$ $(p<0.0001), I^{2}=93.3 \%$. c Forest plot for change in HbAlc at 2-4 months in children and adolescent subjects using random effects model. The areas of the squares are proportional to the weight of the study. Nine studies with 2-4-month outcomes data were included in the analysis. For children and adolescents, overall mean change in HbAlc was $-0.54,95 \%$ CI $-0.84,-0.23$. Heterogeneity: $\tau^{2}=0.11, Q=130.3(p<0.0001), I^{2}=93.9 \%$ 


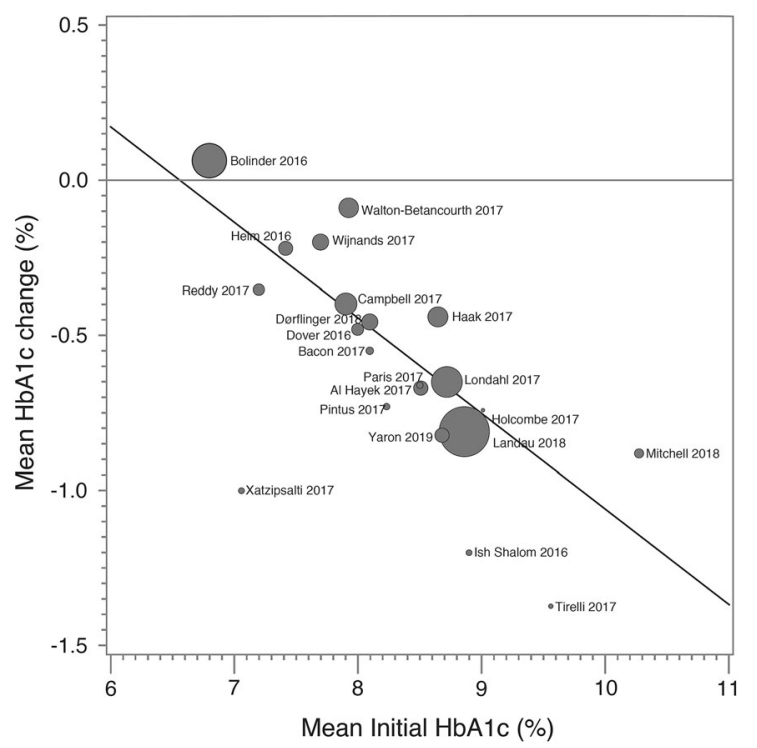

Fig. 4 Bubble chart of mean change in HbAlc at 2-4 months versus mean initial HbAlc. The area of each bubble represents the weight of the study. The regression line from meta-regression random effects model is displayed for 21 studies with 2-4-month outcomes data. Slope $=-0.31(\mathrm{SE}=0.056,95 \% \mathrm{CI}-0.43$ to -0.19$)$. Mean initial HbAlc explains a considerable proportion of the heterogeneity between trials in change in HbAlc. Homogeneity: $\quad \tau^{2}=0.02, \quad Q=56.2 \quad(p<0.0001)$, $I^{2}=66.2 \%$. On average, for each percentage increase in mean initial $\mathrm{HbAlc}$, the mean change in final $\mathrm{HbAlc}$ drops by $0.31 \%, 95 \% \mathrm{CI}-0.43$ to -0.19 . For example, this analysis indicates that if the mean initial HbAlc is $8.5 \%$, the expected mean reduction in $\mathrm{HbA} 1 \mathrm{c}$ is $0.6 \%$, a final $\mathrm{HbA} 1 \mathrm{c}$ of $7.9 \%$

RCTs and real-world observational studies included in this meta-analysis show a dependency on mean initial HbA1c amongst the study population in each case. Overall, for each percentage increase in mean initial HbA1c, the mean change in final HbA1c over 2-4 months falls by $0.31 \%$. Limitations of our meta-analysis are that the recruitment of subjects into the included observational studies was not standardised, only flash glucose monitoring arms were considered and publication bias may be present (Fig. 2). However, these data using the Freestyle Libre system are consistent with the findings from RCTs using traditional CGM. The DIAMOND study on T1D [5] reported that the change in HbA1c from baseline at 24 weeks in

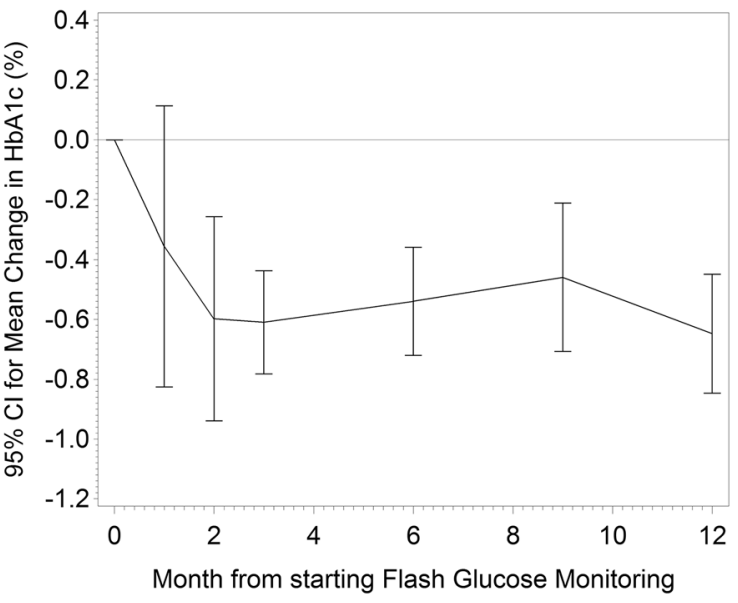

Fig. 5 Mean change in HbAlc with flash glucose monitoring is sustained over 12 months in adult subjects. HbAlc is significantly reduced from 2 months onwards in adult subjects. No significant differences were detected between type 1 and type 2 diabetes (95\% CI -0.51 to $0.17, p=0.2883)$. HbAlc level reduces each month to approximately 2 months, after which the reduction is maintained to 12 months

subjects with an initial HbA1c $\geq 8.5 \%$ (average $9.1 \%$ ) was $-0.8 \%$ (mean adjusted difference) whereas the change in HbA1c for subjects with an initial $\mathrm{HbA} 1 \mathrm{c}<8.5 \%$ (average $8.0 \%$ ) was $-0.4 \%$. Similarly, our meta-analysis in adults with T1D or T2D indicates that if the mean initial $\mathrm{HbA} 1 \mathrm{c}$ is $9.1 \%$ or $8.0 \%$, the expected mean reduction in $\mathrm{HbA} 1 \mathrm{c}$ is $0.8 \%$ or $0.4 \%$, respectively. No improvement in HbA1c (zero change) was achieved when mean initial HbA1c were $6.6 \%$ overall, $6.6 \%$ in adults and $6.5 \%$ in children.

An important finding from our meta-analysis is that the reduction in mean HbA1c with the FreeStyle Libre system was rapid in onset (significant from 2 months onwards) and sustained (Fig. 5). No significant differences were detected between T1D and T2D. However, the majority of subjects across the studies in this meta-analysis were adults with T1D, which limits the ability to detect differences between T1D and T2D. We were not able to present the longitudinal pattern in children because of the limited number of trials reporting multiple time points (two trials) that would, to a large extent, characterise the changes between months. 
The substantial heterogeneity apparent between the studies analysed here $\left(I^{2}=94.1 \%\right)$ was expected and reflects the differences in study design and recruitment, the length of each study and the mean $\mathrm{HbA1c}$ prior to starting the FreeStyle Libre system. A random effects model was used to allow for this heterogeneity, as is accepted for such an analysis. This heterogeneity is a limitation of the meta-analysis as undertaken here and is an acknowledged limitation of observational studies in general $[12,13]$. However, we have identified that initial HbA1c is a significant contributor to the observed heterogeneity. By accounting for this through the regression analysis of overall mean change in HbA1c over 2-4 months with the FreeStyle Libre system as a function of initial HbA1c, we can report a much reduced heterogeneity $\left(I^{2}=66.2 \%\right)$, which is considered to be moderate and acceptable within the context of a meta-analysis. While acknowledging the limitations of using real-world observational data (Fig. 2), this meta-analysis supports the conclusion that there was a consistent improvement in HbA1c from baseline that was dependent on the initial HbA1c.

The impact of rapid treatment decisions on patient health and wellbeing means that the value of new treatment modalities must be confirmed in a timely fashion. In this context, the increasing importance of observational studies within meta-analyses is recognised $[12,13]$. A key aspect of guidance on inclusion of observational studies with inherent heterogeneity is the obligation to consider alternative hypotheses for the treatment effect proposed. Because 19 of the 21 studies reported in Fig. 3 are interpreted to be prospective in design, the most obvious alternative explanation of the consistent reduction in $\mathrm{HbA1c}$ seen across the studies reported here is a study effect in which, because the subjects are aware of their inclusion in the study, this has then prompted a significant change in self-care, independent of the capabilities of the FreeStyle Libre technology itself. However, we argue against this for several reasons. Firstly, across the studies included, no evidence of specific changes in standard selfcare were reported that might result in improved HbA1c. Rather, where noted, SMBG testing frequencies decreased [9-11, 17, 29]. Secondly, the longitudinal analysis on adult subjects (Fig. 5) shows that the reduction in HbA1c is sustained over 12 months, which is less likely to be a study effect. Lastly, the FreeStyle Libre system when used as indicated is not a passive intervention. It provides users with a series of active glycaemic measures at the point of scanning, along with summary reports on recent glucose performance. Only if blinded to this information could a study effect truly hold sway.

Despite its importance, HbA1c is only one metric of glycaemic health. The FreeStyle Libre system has already been shown to reduce the amount of time that adults with T1D or T2D on insulin spend with glucose in the hypoglycaemic zone below $3.9 \mathrm{mmol} / \mathrm{L} \quad(70 \mathrm{mg} / \mathrm{dL})$ $[10,11]$, with significant improvements both in daytime and nocturnal hypoglycaemia. Similarly, adults, children and adolescents with T1D see reductions in measures of glycaemic variability with the FreeStyle Libre system, as do adults with T2D on insulin [9-11].

\section{CONCLUSIONS}

The meta-analysis of 25 real-world observational studies and RCTs reported here confirms that starting the FreeStyle Libre flash glucose monitoring system as part of daily diabetes care results in a significant reduction in $\mathrm{HbA1c}$ for adults and children with T1D and for adults with T2D. A longitudinal analysis of the data for adult subjects with T1D or T2D showed that using the FreeStyle Libre system results in a rapid and sustained reduction in HbA1c. The degree of change in $\mathrm{HbA1c}$ is predicted by the HbA1c at baseline, such that study subjects with a higher initial HbA1c achieved, on average, a greater reduction in HbA1c over the intervention period. The reductions in laboratory HbA1c reported here for the FreeStyle Libre flash glucose monitoring system are comparable to those previously reported for other CGM devices. The inclusion of real-world observational data within any meta-analysis and potential publication bias are acknowledged limitations of this analysis [12]. However, together with previously 
published RCT data for the FreeStyle Libre system, this meta-analysis confirms that flash glucose monitoring technology has a positive impact on glucose control, limiting glucose variability, reducing hypoglycaemia and improving long-term glucose control as measured by HbA1c.

\section{ACKNOWLEDGEMENTS}

Funding. Funding for this meta-analysis, the preparation of the manuscript and the journal's Rapid Service Fee were provided by Abbott Diabetes Care.

Editorial Assistance. Support for the writing of the manuscript was provided by Dr Robert Brines of Bite Medical Consulting, which was paid for by Abbott Diabetes Care.

Authorship. All named authors meet the International Committee of Medical Journal Editors (ICMJE) criteria for authorship for this article, take responsibility for the integrity of the work as a whole, and have given their approval for this version to be published.

Disclosures. Zoë Welsh is an employee of Abbott Diabetes Care. Sara Ells is an employee of Abbott Diabetes Care. Alexander Seibold is an employee of Abbott Diabetes Care. Mark Evans has been a member of advisory panels/received speakers fees and travel support from NovoNordisk; member of advisory panel/speakers fees for Abbott Diabetes Care, Eli Lilly, Roche; member of advisory panel for Medtronic, CellNovo, Dexcom; received speakers fees from MSD, Astra Zeneca; collaborated in research studies/acted as a clinical triallist for MedImmune, Boehringer Ingelheim, NovoNordisk, Sanofi Aventis.

Compliance with Ethics Guidelines. This article is based on previously conducted studies and does not contain any studies with human participants or animals performed by any of the authors.
Data Availability. The datasets analyzed during the current study are available from the corresponding author on reasonable request.

Open Access. This article is distributed under the terms of the Creative Commons Attribution-NonCommercial 4.0 International License (http://creativecommons.org/licenses/ by-nc/4.0/), which permits any noncommercial use, distribution, and reproduction in any medium, provided you give appropriate credit to the original author(s) and the source, provide a link to the Creative Commons license, and indicate if changes were made.

\section{REFERENCES}

1. The Diabetes Control and Complications Trial Research Group. The effect of intensive treatment of diabetes on the development and progression of long-term complications in insulin-dependent diabetes mellitus. N Engl J Med. 1993;329:977-86.

2. UK Prospective Diabetes Study (UKPDS) Group. Intensive blood-glucose control with sulphonylureas or insulin compared with conventional treatment and risk of complications in patients with type 2 diabetes (UKPDS 33). Lancet. 1998;352:837-53.

3. Holman RR, et al. 10-year follow-up of intensive glucose control in type 2 diabetes. $\mathrm{N}$ Engl J Med. 2008;359:1577-89.

4. The Juvenile Diabetes Research Foundation Continuous Glucose Monitoring Study Group. Continuous glucose monitoring and intensive treatment of type 1 diabetes. N Engl J Med. 2008;359:1464-76.

5. Beck RW, Riddlesworth T, Ruedy K, et al. Effect of continuous glucose monitoring on glycemic control in adults with type 1 diabetes using insulin injections. The DIAMOND randomized clinical trial. JAMA. 2017;317:371-8.

6. Beck RW, Riddlesworth T, Ruedy K, et al. Continuous glucose monitoring versus usual care in patients with type 2 diabetes receiving multiple daily insulin injections: a randomized trial. Ann Intern Med. 2017;167:365-74.

7. Lind M, Polonsky W, Hirsch IB, et al. Continuous glucose monitoring vs conventional therapy for glycemic control in adults with type 1 diabetes treated with multiple daily insulin injections: the 
GOLD randomized clinical trial JAMA. 2017;317:379-87.

8. Battelino T, Conget I, Olsen B, et al. The use and efficacy of continuous glucose monitoring in type 1 diabetes treated with insulin pump therapy: a randomised controlled trial. Diabetologia. 2012;55:3155-62.

9. Campbell F, Murphy N, Stewart C, et al. Outcomes of using flash glucose monitoring technology by children and young people with type 1 diabetes in a single arm study. Paediatr Diabetes. 2018. https:// doi.org/10.1111/pedi.12735.

10. Bolinder J, Antuna R, Geelhoed-Duijvestijn P, et al. Novel glucose-sensing technology and hypoglycaemia in type 1 diabetes: a multicentre, nonmasked, randomised controlled trial. Lancet. 2016;388:2254-63.

11. Haak T, Hanaire H, Ajjan R, et al. Flash glucosesensing technology as a replacement for blood glucose monitoring for the management of insulintreated type 2 diabetes: a multicenter, open-label randomized controlled trial. Diabetes Ther. 2017;8:55-73.

12. Stroup DF, Berlin JA, Morton SC, et al. Meta-analysis of observational studies in epidemiology: a proposal for reporting. JAMA. 2000;283:2008-12.

13. von Elm E, Altman DG, Egger $M$, et al. The Strengthening the Reporting of Observational Studies in Epidemiology (STROBE) statement: guidelines for reporting observational studies. Int J Surg. 2014;12:1495-9.

14. Gibb FW, Stimson RH, Zammitt NN, et al. Flash glucose monitoring is associated with improved glycaemic control and quality of life in people with type 1 diabetes: a large 'real-world' assessment. Diabetologia. 2018;16(S1):S391.

15. Xatzipsalti M, Mentesidou L, Kourti A, et al. Flash glucose monitoring system improves glycemic control. Pediatr Diabetes. 2017;18(Suppl. 25):78.

16. Reddy M, Jugnee N, El Laboudi A, et al. A randomized controlled pilot study of continuous glucose monitoring and flash glucose monitoring in people with type 1 diabetes and impaired awareness of hypoglycaemia. Diabetes Med. 2018;35:483-90.

17. Moreno-Fernandez J, Pazos-Couselo M, GonzálezRodriguez $\mathrm{M}$, et al. Clinical value of flash glucose monitoring in patients with type 1 diabetes treated with continuous subcutaneous insulin infusion. Endocrinol Diabetes Nutr. 2018;65:556-63.

18. Helm N, De ML, Forsman S, et al. Flash glucose monitoring improves perception and frequency of glucose monitoring leading to improved glucose control. Pediatr Diabetes. 2016;17:115.

19. Messaaoui A, Tentoutasse S, Crenier L. Flash glucose monitoring in children-one-year experience. Diabetes. 2016;67(S1):946.

20. Wijnands A, Gys I, Bevilacqua E, et al. The FreeStyle flash glucose monitoring system has limited effect on the metabolic control of children and adolescents with type 1 diabetes mellitus. Pediatr Diabetes. 2017;18(Suppl. 25):38.

21. McKnight JA, Gibb FW. Flash glucose monitoring is associated with improved glycaemic control but use is largely limited to more affluent people in a UK diabetes centre. Diabetes Med. 2017;34:732. https://doi.org/10.1111/dme.13315.

22. Walton-Betancourth S, Amin R. A clinic-based study of the impact of flash glucose sensing technology on glycaemic control and self-monitoring of blood glucose in children and young people with type 1 diabetes. Pediatr Diabetes. 2017;18(Suppl. 25):47.

23. Dover AR, Stimson RH, Zammitt NN, Gibb FW. Flash glucose monitoring improves outcomes in a type 1 diabetes clinic. J Diabetes Sci Technol. 2017;11(2):442-3.

24. Bacon S, O'Dwyer B, Chambers C, et al. The performance and technical usability of a flash glucometer monitoring system. Irish J Med Sci. 2017;186(9):S357.

25. Dørflinger GH, Østergaard JA, Fisker S, et al. The effect of flash glucose monitoring on glycemic control in patients with type 1 diabetes. Diabetes. 2018;67(S1):942.

26. Pintus D, Ng SM. FreeStyle Libre Flash glucose monitoring (Flash GM) system improves glycaemic control and patient quality of life measures in children with type 1 diabetes with appropriate provision of Flash GM education and support by healthcare professionals. Pediatr Diabetes. 2017;18(S25):eP004.

27. Karlsson E. HbA1c after one year of use of flash glucose monitoring in patients with type 1 diabetes. Thesis, University of Orebero, Sweden.

28. Al Hayek A, Asirvatham RA, Al Dawish M. Evaluation of FreeStyle Libre flash glucose monitoring system on glycemic control, health-related quality of life, and fear of hypoglycemia in patients with type 1 diabetes. Clin Med Insights Endocrinol Diabetes. 2017;10:1-6.

29. Paris I, Henry C, Pirard F, et al. The new FreeStyle Libre flash glucose monitoring system improves the 
glycaemic control in a cohort of people with type 1 diabetes followed in real-life conditions over a period of one year. Endocrinol Diabetes Metab. 2018. https://doi.org/10.1002/edm2.23.

30. Abdalaziz A, Lan K, Bilous $M$, et al. Flash glucose monitoring (FGM) in people with type 1 diabetes: single centre-real-world experience. Diabetes Med. 2018;35(S1):168.

31. Yaron M, Roitman E, Aharon-Hananel G, et al. Intervention of the flash glucose sensing technology on glycemic control and treatment satisfaction in patients with type 2 diabetes treated intensively using insulin: a randomized controlled trial. Diabetes. 2018;67(S1):908.

32. Weiss J, Cohen N, Zajac JD, et al. Flash glucose monitoring-using technology to improve outcomes for patients with diabetes. Aust J Rural Health. 2018;26:453-4.

33. Löndahl M, Filipsson $\mathrm{K}$, Lindholm E, et al. Effect of flash glucose monitoring on metabolic control and self-esteem treatment satisfaction in people with T1DM. Diabetes Technol Ther. 2017;19(S1):A-81.

34. Landau Z, Abiri S, Gruber N, et al. Use of flash glucose-sensing technology (FreeStyle Libre) in youth with type 1 diabetes: aWeSoME study group real-life observational experience. Acta Diabetol. 2018;55:1303-10.

35. Ish-Shalom M, Wainstein J, Raz I, et al. Improvement in glucose control in difficult-to-control patients with diabetes using a novel flash glucose monitoring device. J Diabetes Sci Technol. 2016;5:1572-83.

36. Holcombe A, Karunakaran V, Streeting J, et al. Trial of FreeStyle Libre in a local service: impact on diabetes outcomes. Diabetes Med. 2017;34(S1):160.

37. Tirelli E, Frontino G, Favalli V, et al. Flash glucose monitoring in noncompliant children and adolescents with type 1 diabetes. Diabetes Technol Ther. 2017;19(S1):A-83.

38. Hey C, Alkharaiji M, Anyanwagu U, et al. Impact of FreeStyle Libre on glycaemic control, frequency of glucose monitoring and treatment satisfaction. Diabetes Med. 2018;35(Supplement 1):195.

39. Mitchell K, McDougall C. Trial of FreeStyle Libre flash glucose monitoring (FGM) in patients with poorly controlled type 1 diabetes. Diabetes Med. 2018;35(S1):160.

40. Higgins JPT, Thompson SG, Deeks J, et al. Measuring inconsistency in meta-analysis. BMJ. 2003;327:557-60.

41. Thompson SG, Higgins JPT. How should meta-regression analyses be undertaken and interpreted. Stat Med. 2002;21:1559-73.

42. Sheu C-F, Suzuki S. Meta-analysis using linear mixed models. Behav Res Methods Instrum Comput. 2001;33:102-11. 